\title{
Consequences of Hyperoxia and the Toxicity of Oxygen in the Lung
}

\author{
William J. Mach,, ${ }^{1}$ Amanda R. Thimmesch, ${ }^{1}$ J. Thomas Pierce, ${ }^{2}$ and Janet D. Pierce ${ }^{1}$ \\ ${ }^{1}$ School of Nursing, University of Kansas, 3901 Rainbow Boulevard, Kansas City, KS 66160, USA \\ ${ }^{2}$ U.S. Department of Veterans Affairs (122), Rehabilitation Research and Development Service, 810 Vermont Avenue, NW, Washington, \\ DC 20420, USA
}

Correspondence should be addressed to Amanda R. Thimmesch, athimmesch@kumc.edu

Received 14 December 2010; Revised 29 March 2011; Accepted 4 April 2011

Academic Editor: Alan Pearson

Copyright (C) 2011 William J. Mach et al. This is an open access article distributed under the Creative Commons Attribution License, which permits unrestricted use, distribution, and reproduction in any medium, provided the original work is properly cited.

Oxygen $\left(\mathrm{O}_{2}\right)$ is life essential but as a drug has a maximum positive biological benefit and accompanying toxicity effects. Oxygen is therapeutic for treatment of hypoxemia and hypoxia associated with many pathological processes. Pathophysiological processes are associated with increased levels of hyperoxia-induced reactive $\mathrm{O}_{2}$ species (ROS) which may readily react with surrounding biological tissues, damaging lipids, proteins, and nucleic acids. Protective antioxidant defenses can become overwhelmed with ROS leading to oxidative stress. Activated alveolar capillary endothelium is characterized by increased adhesiveness causing accumulation of cell populations such as neutrophils, which are a source of ROS. Increased levels of ROS cause hyperpermeability, coagulopathy, and collagen deposition as well as other irreversible changes occurring within the alveolar space. In hyperoxia, multiple signaling pathways determine the pulmonary cellular response: apoptosis, necrosis, or repair. Understanding the effects of $\mathrm{O}_{2}$ administration is important to prevent inadvertent alveolar damage caused by hyperoxia in patients requiring supplemental oxygenation.

\section{Introduction}

When administering supplemental oxygen $\left(\mathrm{O}_{2}\right)$ to treat hypoxemia associated with acute and chronic conditions, $\mathrm{O}_{2}$ toxicity by overexposure may be present. Annually, the need for supplemental $\mathrm{O}_{2}$ is projected to be around 800,000 individuals at a cost of 1.8 billion dollars [1]. Suboptimal use of $\mathrm{O}_{2}$ is reflected in prescription and treatment errors that exceed those related to antibiotics [2-4].

The alveolar epithelial and alveolar capillary endothelial cells are vulnerable targets for $\mathrm{O}_{2}$-free-radical-induced injury caused by hyperoxia. In acute lung injury (ALI) caused by hyperoxia, hyperpermeability of the pulmonary microvasculature causes flooding of the alveolus with plasma extravasations leading to pulmonary edema and abnormalities in the coagulation and fibrinolysis pathways promoting fibrin deposition $[5,6]$. Type II alveolar epithelial cells are injured by $\mathrm{O}_{2}$ free radicals leading to impairment of surfactant production [7]. Thus, the maximum positive biological benefit for this life essential but toxic molecule exists along a doseresponse, deficiency-toxicity continuum.

\section{Pathophysiology of Oxygen Toxicity}

Hyperoxia is a state of excess supply of $\mathrm{O}_{2}$ in tissues and organs. Oxygen toxicity occurs when the partial pressure of alveolar $\mathrm{O}_{2}\left(\mathrm{P}_{\mathrm{A}} \mathrm{O}_{2}\right)$ exceeds that which is breathed under normal conditions. With continuous exposure to supraphysiologic concentrations of $\mathrm{O}_{2}$, a state of hyperoxia develops. Under hyperoxic pathological conditions, a large influx of reactive $\mathrm{O}_{2}$ species (ROS) are produced. In intracellular and extracellular biological systems, the mass effect of ROS elevation, caused by $\mathrm{O}_{2}$ overexposure, disrupts the balance between oxidants and antioxidants, and this disruption of homeostasis can result in damage to cells and tissues [8-11].

Exposure time, atmospheric pressure, and fraction of inspired $\mathrm{O}_{2}\left(\mathrm{FIO}_{2}\right)$ determine the cumulative $\mathrm{O}_{2}$ dose leading 
to toxicity. Oxygen is toxic to the lungs when high $\mathrm{FIO}_{2}$ $(>0.60)$ is administered over extended exposure time $(\geq 24$ hours) at normal barometric pressure ( 1 atmospheres absolute (ATA)). This type of exposure is referred to as low pressure $\mathrm{O}_{2}$ poisoning, pulmonary toxicity, or the Lorraine Smith effect. Oxygen exposure after approximately 12 hours leads to lung passageway congestion, pulmonary edema, and atelectasis caused by damage to the linings of the bronchi and alveoli. The formation of fluid in the lungs causes a feeling of shortness of breath combined with a burning of the throat and chest, and breathing becomes very painful [12]. The reason for this effect in the lungs but not in other tissues is that the air spaces of the lungs are directly exposed to the high $\mathrm{O}_{2}$ pressure. Oxygen is delivered to the other body tissues at almost normal partial pressure of $\mathrm{O}_{2}\left(\mathrm{PO}_{2}\right)$ because of the hemoglobin- $\mathrm{O}_{2}$ buffer system [13-15]. Toxicity also occurs when the ATA is high (1.6-4) and the high $\mathrm{FIO}_{2}$ exposure time is short. This type of exposure is referred to as high pressure $\mathrm{O}_{2}$ poisoning or the Paul Bert effect and is toxic to the central nervous system (CNS). Central nervous system toxicity results in seizures followed by coma in most people within 30 to 60 minutes. Seizures often occur without warning and are likely to be lethal. Other symptoms include nausea, muscle twitching, dizziness, disturbances of vision, irritability, and disorientation [13, 16-20]. Oceanic divers are more likely to experience CNS toxicity [17].

Pulmonary capillary endothelial and alveolar epithelial cells are targets for ROS resulting in injury-induced lung edema, alveolar flooding, hemorrhage, and collagen, elastin, and hyaline membrane deposits $[11,21,22]$. Above a critical $\mathrm{P}_{\mathrm{A}} \mathrm{O}_{2}$, the hemoglobin- $\mathrm{O}_{2}$ buffering mechanism fails and the tissue $\mathrm{PO}_{2}$ can rise to hundreds or thousands of $\mathrm{mm} \mathrm{Hg}$. At high levels of $\mathrm{O}_{2}$, protective endogenous antioxidant enzyme systems become consumed by ROS leading to cell death [16, 23].

Oxygen toxicity caused by ROS progresses in overlapping phases based on degree of severity and reversibility of injury. The phases are initiation, inflammation, proliferation, and fibrosis. Initially, there are increased ROS and depleted antioxidant levels, and the lung fails to clear itself of mucous. The inflammation phase or exudative phase is characterized by the destruction of the pulmonary lining and migration of leukocyte derived inflammatory mediators to the sites of injury. The proliferative phase is subacute and there are cellular hypertrophy, increased secretions from surfactant secreting alveolar type II cells, and increased monocytes. The final terminal phase is the fibrotic phase in which the changes to the lung are irreversible and permanent. There is collagen deposition and thickening of the pulmonary interstitial space and the lung becomes fibrotic [24-27].

Clinically, progressive hypoxemia, or high $\mathrm{O}_{2}$ tension in the blood, requires increased $\mathrm{FIO}_{2}$ and assisted ventilation, which further aggravate the pathophysiological changes associated with $\mathrm{O}_{2}$ toxicity. Chest $\mathrm{X}$-rays may show an alveolar interstitial pattern in an irregular distribution with evidence of a moderate loss of volume from atelectasis, however there is no clinical way of diagnosing $\mathrm{O}_{2}$ toxicity. Lung biopsy specimens may show changes consistent with $\mathrm{O}_{2}$ toxicity but the primary value of the biopsy is to exclude other causes of lung injury. Air pressure changes within the enclosed lung cavity and ventilator-induced injury may accompany and be indistinguishable from $\mathrm{O}_{2}$ toxicity. Oxygen toxicity can be minimized by keeping the $\mathrm{P}_{\mathrm{A}} \mathrm{O}_{2}$ less than $80 \mathrm{~mm} \mathrm{Hg}$ or the $\mathrm{FIO}_{2}$ below 0.40 to 0.50 [12].

The pulmonary cellular response to hyperoxic exposure and increased ROS is well described. Anatomically, the pulmonary epithelial surface is vulnerable to a destructive inflammatory response. This inflammation damages the alveolar capillary barrier leading to impaired gas exchange and pulmonary edema. Reactive $\mathrm{O}_{2}$ species induces pulmonary cell secretion of chemoattractants, and cytokines stimulate macrophage and monocyte mobilization and accumulation into the lungs, leading to additional ROS. The ROS leukocyte interaction further exacerbates injury. Research has shown that as these highly reduced cell layers become increasingly oxidized and levels of antioxidants fall, ROS-induced activation of multiple upstream signal transduction pathways regulates the cellular response: adaptation, repair, or cell death by apoptosis, oncosis, or necrosis [28, 29].

Mitogen-activated protein kinase (MAPK), toll-like receptor 4 (TLR4), signal transducers and activators of transcription (STAT), and nuclear factor kappa beta (NF k $\beta$ ) are a few well-researched protein pathways that communicate the receptor signal to the deoxyribonucleic acid (DNA) of the cell thereby determining the cellular response. The MAPK pathway is a regulator of cell death genes, stress, and transformation and growth regulation. Mitogen-activated protein kinase activation precedes extracellular signal regulated kinase (ERK1/2), a promoter of cell proliferation. C-Junterminal protein kinase $(\mathrm{JNK} 1 / 2)$ and p38 kinase both induce cell death and inflammation [30]. The TLR4, STAT, and nuclear regulatory factor 2 (Nrf2) pathways are associated with survival gene expression such as caspase-3 proteins and antioxidant response element (ARE) [31, 32]. The NF $\mathrm{k} \beta$ pathway is an up-stream signal for inflammation and survival genes: anti-oxidant enzymes (AOE), Bcl-2, AKT, heme oxygenase (HO-1), and heat shock proteins (HSPs). The $\mathrm{AKT}_{1-4}$ family of signals plays an important role in glucose metabolism, cell proliferation, apoptosis, transcription, and cell migration. The Bcl-2 proteins are antiapoptotic while HO-1 and HSPs are ubiquitous stress-response proteins [33]. These signaling pathways are regulators of the pulmonary epithelial cell response to increases in ROS and hyperoxia $[18,34]$. Cytokine and chemokine overexpression in response to hyperoxic stress can be protective. Tumor necrosis factor alpha $(\mathrm{TNF} \alpha)$, interleukin 1 beta (IL-1 $\beta)$, interleukin 6 (IL-6), chemokine receptor 2 (CXCR2), interleukin 11 (IL-11), insulin and keratinocyte growth factor expression, and the beta subunit of $\mathrm{Na}, \mathrm{K}$-ATPase have been shown to attenuate death signals [35-37].

\section{The Formation of Free Radicals}

Oxygen is a requirement for cellular respiration in the metabolism of glucose and the majority of $\mathrm{O}_{2}$ consumed by the mitochondria is utilized for adenosine triphosphate (ATP) generation [38, 39]. The mitochondrial electron transport 
chain reduces the elemental molecular $\mathrm{O}_{2}$ to ionic $\mathrm{O}_{2}$ by the relay of electrons making $\mathrm{O}_{2}$ usable for ATP generation, during this process, oxidizing free radicals are generated $[40,41]$. Toxic levels of $\mathrm{O}_{2}$ lead to the formation of additional ROS, which can impose damage to lipid membranes, proteins, and nucleic acids. Reactive $\mathrm{O}_{2}$ species mediate physiological and pathophysiological roles within the body [42].

Free radicals are a type of unstable, reactive, short-lived chemical species that have one or more unpaired electrons and may possess a net charge or be neutral. The species is termed free because the unpaired electron in the outer orbit is free to interact with surrounding molecules [42, 43]. Cells generate free radicals, or ROS, by the reduction of molecular $\mathrm{O}_{2}$ to water $\left(\mathrm{H}_{2} \mathrm{O}\right)$ (Figure 1) $[44,45]$.

Chemically, three types of reactions lead to the formation of ROS. The one-electron reduction of molecular $\mathrm{O}_{2}$ to the superoxide anion $\left(\mathrm{O}_{2}^{-\bullet}\right)$ is catalyzed by transition metals including iron $(\mathrm{Fe})$ and copper $(\mathrm{Cu})$ such as

$$
\mathrm{Fe}^{\mathrm{II}}+\mathrm{O}_{2} \longrightarrow \mathrm{Fe}^{\mathrm{III}}+\mathrm{O}_{2}^{-\bullet} \text {. }
$$

The simultaneous oxidation reduction reaction of $\mathrm{O}_{2}{ }^{-\bullet}$ to hydrogen peroxide $\left(\mathrm{H}_{2} \mathrm{O}_{2}\right)$ and the addition of an electron to $\mathrm{O}_{2}{ }^{-\bullet}$ produce the hydroxyl radical $(\mathrm{HO} \cdot)$. The $\mathrm{O}_{2}{ }^{-\bullet}$ in biological membranes can act in four different modes: electron transfer, nucleophilic substitution, deprotonation, and a hydrogen atom abstraction as in

$$
\mathrm{O}_{2}^{-\bullet}+\mathrm{O}_{2}^{-\bullet}+2 \mathrm{H}^{+} \longrightarrow \mathrm{H}_{2} \mathrm{O}_{2}+\mathrm{O}_{2} \text {. }
$$

$\mathrm{A} \mathrm{O}_{2}{ }^{-\bullet}$ initiated Fenton-type reaction and the decomposition of $\mathrm{H}_{2} \mathrm{O}_{2}$ requires $\mathrm{O}_{2}{ }^{-\bullet}$ and $\mathrm{H}_{2} \mathrm{O}_{2}$ as precursors and $\mathrm{Fe}$ and $\mathrm{Cu}$ presence for completion. The $\mathrm{HO}^{\bullet}$ is the most injury producing in biological systems, reacting with molecules in close proximity. These reactions are called Fenton-like reactions generating $\mathrm{O}_{2}$ and $\mathrm{HO}^{\bullet}$ when $\mathrm{Fe}^{\mathrm{II}}$ or $\mathrm{Cu}^{\mathrm{I}}$ reacts with $\mathrm{H}_{2} \mathrm{O}_{2}$

$$
\begin{gathered}
\mathrm{Fe}^{\mathrm{III}}+\mathrm{O}_{2}^{-\bullet} \longrightarrow \mathrm{Fe}^{\mathrm{II}}+\mathrm{O}_{2} \\
\mathrm{Fe}^{\mathrm{II}}+\mathrm{H}_{2} \mathrm{O}_{2} \longrightarrow \mathrm{Fe}^{\mathrm{III}}+\mathrm{HO}^{\bullet}+\mathrm{HO}^{\bullet} \\
\mathrm{O}_{2}^{-\bullet}+\mathrm{H}_{2} \mathrm{O}_{2} \longrightarrow \mathrm{O}_{2}+\mathrm{HO}^{\bullet}+\mathrm{HO}^{\bullet}
\end{gathered}
$$

The sum of reactions (3) and (4), or the Haber-Weiss reaction shown in (5) above demonstrates $\mathrm{HO}^{\circ}$ formation by the metal-catalyzed decomposition of $\mathrm{H}_{2} \mathrm{O}_{2}$. The interaction between $\mathrm{O}_{2}{ }^{-\bullet}$ and $\mathrm{H}_{2} \mathrm{O}_{2}$ is the source of the majority of damage to biological systems due to the reactivity of continuously produced, highly toxic $\mathrm{HO}^{\bullet}[18,46,47]$. These ROSproducing reactions occur endogenously involving enzymes, neutrophils, and organelles such as the mitochondria and exogenously induced by radiation, pollutants, xenobiotics, and toxins. Cellular survival and adaptation in an oxidative atmosphere are dependent upon sufficient antioxidant defenses to counteract the effects of ROS on cells and tissues [48].

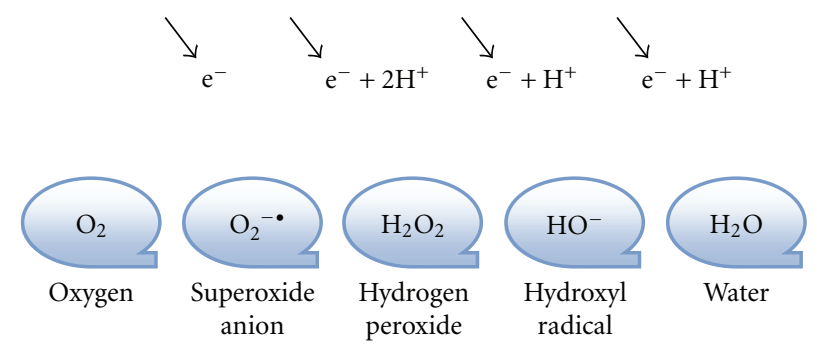

Figure 1: Reduction of oxygen. A single-electron transfer which converts molecular oxygen to the superoxide anion, creating an unstable molecule. The decomposition of hydrogen peroxide can be a source of the hydroxyl radical; this reaction requires both superoxide and hydrogen peroxide as precursors. These steps reduce oxygen to water by the addition of four electrons, yielding three reactive oxygen species: superoxide anion, hydrogen peroxide, and hydroxyl radical.

\section{Functions and Classifications of Antioxidants}

Oxidant antioxidant homeostasis is highly regulated and essential for maintaining cellular and biochemical functions [49]. A change in the balance toward an increase in the oxidant over the capacity of the antioxidant defines oxidative stress and can lead to oxidative damage. Changing the balance toward an increase in the reducing power of the antioxidant can also cause damage and is defined as reductive stress [50-52]. Reduction, antioxidant and oxidation, or prooxidant reactions result from a gain or a loss of electrons and a loss or a gain in $\mathrm{O}_{2}[50,53,54]$.

An antioxidant (a reductant or reducing agent) is anything that can prevent or inhibit oxidation [55-57]. Delay of oxidation can be achieved by preventing the generation or inactivating ROS [58]. Prevention, diversion, dismutation (decay), scavenging, and quenching are specialized antioxidant properties (Table 1). Antioxidant defenses may be classified as nonenzymatic and enzymatic or endogenous and dietary. Examples of nonenzymatic antioxidants are glutathione (GSH), ascorbic acid, vitamin E, beta-carotene, and uric acid. Major enzymatic antioxidants are superoxide dismutase (SOD), catalase, and GSH peroxidase which divert or dismutate ROS into harmless products. Endogenous or dietary antioxidants are based on the ability of the antioxidant to be synthesized by humans. Endogenous antioxidants are SOD, catalase, GSH peroxidase, uric acid, and bilirubin. Dietary antioxidants are ascorbic acid, vitamin E, and beta-carotene $[59,60]$. Ascorbic acid, vitamin E, uric acid, bilirubin, and GSH scavenge ROS by expendable, replaceable, or recyclable substrates. Vitamin E and beta-carotene quench ROS by absorption of electrons and/or energy.

Antioxidants can be classified into four categories based on function. (1) Preventive antioxidants which suppress formation of ROS, (2) radical scavenging antioxidants which suppress chain initiation and/or break chain propagation reactions, (3) the repair and de novo antioxidants such as proteolytic enzymes and the repair enzymes of DNA, and (4) antioxidants which allow for adaptation that occurs when 
TABLE 1: Locations and properties of antioxidants.

\begin{tabular}{|c|c|}
\hline \multicolumn{2}{|c|}{ Enzymatic antioxidants located in mitochondria and cytosol } \\
\hline Glutathione peroxidase (GSH) & Removal of $\mathrm{H}_{2} \mathrm{O}_{2}$, hydroperoxides \\
\hline Superoxide dismutase (SOD) & Catalytic removal of $\mathrm{O}_{2}$ \\
\hline Catalase (CAT) & Catalytic reduction of $\mathrm{H}_{2} \mathrm{O}_{2}$ to $\mathrm{H}_{2} \mathrm{O}$ \\
\hline \multicolumn{2}{|c|}{ Nonenzymatic antioxidants located in cell membrane, exogenous dietary source } \\
\hline Vitamin $\mathrm{E}$ ( $\alpha$ tocopherol) & Chain-breaking antioxidant \\
\hline$\beta$-carotene & Scavenger of ROS, singlet $\mathrm{O}_{2}$ quencher \\
\hline Co-enzyme Q & Regenerates vitamin $\mathrm{E}$ \\
\hline \multicolumn{2}{|c|}{ Compounds that reduce the availability of transition metals, Fenton reactions } \\
\hline Transferrin & Sequesters iron and copper ions \\
\hline Lactoferrin & Sequesters iron at lower $\mathrm{pH}$ \\
\hline Albumin & Sequesters heme and copper \\
\hline Ceruloplasmin (ferroxidase) & Scavenges superoxide radical, binds copper ions \\
\hline \multicolumn{2}{|c|}{ Scavengers, products of metabolism, exogenous dietary source } \\
\hline Bilirubin & Scavenges peroxyl radical \\
\hline Uric acid & Scavenges hydroxyl radical \\
\hline Vitamin C (ascorbic acid) & Scavenges hydroxyl radical, recycles vitamin E \\
\hline \multicolumn{2}{|c|}{ Thiol group donors } \\
\hline Reduced glutathione (GSSH) & Binds free radicals, SH group oxidized to disulfide group (GSSG) \\
\hline$\alpha$-lipoic acid & Recycles vitamin C, glutathione substitute \\
\hline
\end{tabular}

the signal for the production and reactions of ROS induces oxidant formation and transport $[10,61]$.

Superoxide dismutase converts $\mathrm{O}_{2}{ }^{--}$to $\mathrm{H}_{2} \mathrm{O}_{2}$ and has three isoforms widely distributed in mammalian organisms. (1) Cytoplasmic SOD (SOD1 or Cu zinc (CuZn) SOD) is located in the cytoplasm, nucleus, and peroxisomes, (2) mitochondrial SOD (SOD2 or MnSOD) is located in the mitochondrial matrix near the electron transport chain, and (3) extracellular SOD (SOD3 or EcSOD) is found in the extracellular fluids and extracellular matrix of all human tissues especially the heart, placenta, pancreas, and lung [62-64]. The protective effects of EcSOD in the lungs are extremely important and well-established [65-68].

Catalase, one of the most potent catalysts found mostly in the peroxisome, functions to decompose $\mathrm{H}_{2} \mathrm{O}_{2}$ to $\mathrm{H}_{2} \mathrm{O}$. Catalase defense from oxidant injury to lung epithelial cells exists in the cytosol or the mitochondria.

Glutathione reductase is an important antioxidant enzyme for maintaining the intracellular reducing environment. This enzyme catalyzes the reduction of glutathione disulfide (GSSG) to GSH [69]. Glutathione disulfide is produced through the oxidation of GSH by ROS that arise during conditions of oxidative stress. Due to the high concentrations of GSH, GSH/GSSG is considered to be the principal redox buffer of the cell and the ratio of GSH/GSSG is viewed as a major indicator of the cellular redox status. The ratio of GSH/GSSG decreases under an oxidative stress condition [70, 71]. Tissue damage may develop when an oxidant/antioxidant imbalance occurs as a consequence of hyperoxia [72, 73]. The damaging effects of hyperoxia can lead to $\mathrm{O}_{2}$ toxicity, cell death, and can be a triggering factor in ALI [22].

\section{Clinical Presentation of Hyperoxic Acute Lung Injury}

Acute lung injury and acute respiratory distress syndrome (ARDS) are secondarily occurring, inflammatory syndromes caused by triggers or risk factors described as direct or indirect, pulmonary or extrapulmonary. The pathological changes associated with HALI mimic the ALI triggered by other conditions such as hemorrhagic shock, reperfusion injury, pneumonia, sepsis, or paraquat inhalation $[23,33$, $74,75]$. The risk of developing ALI or ARDS after inhalation injury is dependent on the toxicity and concentration of the inhaled substance [17]. For example, the cells and structure of the alveolar capillary membrane are highly susceptible to damage by toxic levels of $\mathrm{O}_{2}$ [76]. Both ALI and ARDS are the same clinical disorder, differing only in severity of hypoxemia. The ratio between arterial pressure of $\mathrm{O}_{2}\left(\mathrm{PaO}_{2}\right)$ and the $\mathrm{FIO}_{2}$ concentration delivered by ventilator support distinguishes the two syndromes. For ALI, the $\mathrm{PaO}_{2} / \mathrm{FIO}_{2}$ is $\leq 300 \mathrm{~mm} \mathrm{Hg}$ and for ARDS, the $\mathrm{PaO}_{2} / \mathrm{FIO}_{2}$ is $\leq 200 \mathrm{~mm} \mathrm{Hg}$ $[74,75,77]$.

The injury to the alveolus is thought to develop when pulmonary or systemic inflammation leads to systemic release of cytokines and other proinflammatory molecules. Mast cells, which express mediators that exert effects on lung vasculature, are also increased after hyperoxic exposure [78]. Cytokine release activates alveolar macrophages and recruits neutrophils to the lungs. Subsequent activation of leukotrienes, oxidants, platelet activating factor, and protease occurs. These substances damage capillary endothelium and alveolar epithelium, disrupting the barriers between the capillaries and air spaces. Edema fluid, proteins, and cellular 
debris flood the air spaces and interstitium, causing disruption of surfactant, airspace collapse, ventilation-perfusion mismatch, shunting, and stiffening of the lungs with decreased compliance and pulmonary hypertension. There is no pattern to the injury; however, dependant lung areas are most frequently affected $[74,79]$.

Tissue examination reveals that surfactant disruption, epithelial injury, and sepsis initiate the increased expression of cytokines that sequester and activate inflammatory cells. Increased release of ROS alters normal endothelial function. Microarray analysis has revealed increased expression of genes related to oxidative stress, antiproteolytic function, and extracellular matrix repair as well as decreased surfactant proteins in ozone-induced ALI [80]. Diffuse alveolar damage results with intra-alveolar neutrophils indicating the presence of an inflammatory response in the alveoli. Red blood cells, cellular fragments, and eroded epithelial basement membranes are present with formation of hyaline membranes, indicating that serum proteins have entered and precipitated in the air spaces due to disruption of the alveolar capillary barrier. Formation of microthrombi indicates the presence of endothelial injury and activation of the coagulation cascade [81].

Acute lung injury syndrome presents within 24 to 48 hours after the direct or indirect trigger. Initially, the patient may experience dyspnea, cough, chest pain, tachypnea, tachycardia, accessory muscle use, cyanosis, mottled skin, and abnormal breath sounds (crackles, rhonchi, and wheezing). Blood gas analysis reveals progressive worsening of hypoxemia, leading to respiratory failure. Bilateral infiltrates are seen on a chest X-ray and are consistent with pulmonary edema but without the cardiac component of elevated left atrial pressure. Treatment includes mechanical ventilation, supportive care, and treatment of the underlying causes [16]. The mortality of ALI has improved over the past decade; however, it still ranges from $30 \%$ to $75 \%[75,77,82,83]$ and occurs in about 86 of 100,000 individuals per year [84].

\section{Conclusion}

Oxygen, often used to treat hypoxemia in the clinical setting, is itself a triggering factor in HALI given that the exposure is sufficiently concentrated and of adequate duration. The lung is a vulnerable target for oxidant-induced injury, initiating a cascade of protein signals that determine the cellular response. The alveolar epithelial and alveolar capillary endothelial surfaces are injured. Hyperpermeability, microthrombi (resulting from altered coagulation and fibrinolysis), collagen deposition, and fibrosis alter alveolar structure and function. Understanding precise mechanisms of injury and pulmonary cellular responses to hyperoxia is essential evidence for expert practice.

\section{Acknowledgment}

This project was sponsored by the TriService Nursing Research Program (TSNRP) (N08-012, HU0001-08-1-TS08).
The information or content and conclusions do not necessarily represent the official position or policy of, nor should any official endorsement be inferred by, the TSNRP, the Department of Defense, or the US Government.

\section{References}

[1] V. Kim, J. O. Benditt, R. A. Wise, and A. Sharafkhaneh, "Oxygen therapy in chronic obstructive pulmonary disease," Proceedings of the American Thoracic Society, vol. 5, no. 4, pp. 513$518,2008$.

[2] H. Brokalaki, V. Matziou, S. Zyga et al., "Omissions and errors during oxygen therapy of hospitalized patients in a large city of Greece," Intensive and Critical Care Nursing, vol. 20, no. 6, pp. 352-357, 2004.

[3] S. Hickey, "An audit of oxygen therapy on a respiratory ward," British Journal of Nursing, vol. 16, no. 18, pp. 1132-1136, 2007.

[4] M. Boyle and J. Wong, "Prescribing oxygen therapy. An audit of oxygen prescribing practices on medical wards at north shore hospital, auckland, new zealand," New Zealand Medical Journal, vol. 119, no. 1238, U2080, 2006.

[5] S. Shetty, J. Padijnayayveetil, T. Tucker, D. Stankowska, and S. Idell, "The fibrinolytic system and the regulation of lung epithelial cell proteolysis, signaling, and cellular viability," American Journal of Physiology, vol. 295, no. 6, pp. L967-L975, 2008.

[6] S. Idell, "Coagulation, fibrinolysis, and fibrin deposition in acute lung injury," Critical Care Medicine, vol. 31, no. 4, supplement, pp. S213-S220, 2003.

[7] L. N. Johnson and M. Koval, "Cross-talk between pulmonary injury, oxidant stress, and gap junctional communication," Antioxidants and Redox Signaling, vol. 11, no. 2, pp. 355-367, 2009.

[8] J. Ciencewicki, S. Trivedi, and S. R. Kleeberger, "Oxidants and the pathogenesis of lung diseases," Journal of Allergy and Clinical Immunology, vol. 122, no. 3, pp. 456-470, 2008.

[9] T. L. Clanton, "Hypoxia-induced reactive oxygen species formation in skeletal muscle," Journal of Applied Physiology, vol. 102, no. 6, pp. 2379-2388, 2007.

[10] I. Rahman, S. K. Biswas, and A. Kode, "Oxidant and antioxidant balance in the airways and airway diseases," European Journal of Pharmacology, vol. 533, no. 1-3, pp. 222-239, 2006.

[11] M. Yee, P. F. Vitiello, J. M. Roper et al., "Type II epithelial cells are critical target for hyperoxia-mediated impairment of postnatal lung development," American Journal of Physiology, vol. 291, no. 5, pp. L1101-L1111, 2006.

[12] R. Mason, C. Broaddus, and J. Murray, Murray \& Nadel's Textbook of Respiratory Medicine, vol. 2, 2nd edition, 2005.

[13] H. Zhou, G. M. Saidel, and M. E. Cabrera, "Multi-organ system model of $\mathrm{O}_{2}$ and $\mathrm{CO}_{2}$ transport during isocapnic and poikilocapnic hypoxia," Respiratory Physiology and Neurobiology, vol. 156, no. 3, pp. 320-330, 2007.

[14] R. K. Dash and J. B. Bassingthwaighte, "Simultaneous bloodtissue exchange of oxygen, carbon dioxide, bicarbonate, and hydrogen ion," Annals of Biomedical Engineering, vol. 34, no. 7, pp. 1129-1148, 2006.

[15] N. L. Jones, "An obsession with $\mathrm{CO}_{2}$," Applied Physiology, Nutrition and Metabolism, vol. 33, no. 4, pp. 641-650, 2008.

[16] A. C. Guyton and J. E. Hall, Textbook of Medical Physiology, Elsevier Saunders, Philadelphia, Pa, USA, 11th edition, 2006.

[17] J. Joiner, NOAA Diving Manual: Diving for Science and Technology, Best Publishing Company, Flagstaff, Ariz, USA, 4 th edition, 2001. 
[18] B. Halliwell, "Reactive species and antioxidants. Redox biology is a fundamental theme of aerobic life," Plant Physiology, vol. 141, no. 2, pp. 312-322, 2006.

[19] J. Hedley-Whyte, "Pulmonary oxygen toxicity: investigation and mentoring," Ulster Medical Journal, vol. 77, no. 1, pp. 3942, 2008.

[20] B. W. Allen, I. T. Demchenko, and C. A. Piantadosi, “Two faces of nitric oxide: implications for cellular mechanisms of oxygen toxicity," Journal of Applied Physiology, vol. 106, no. 2, pp. 662$667,2009$.

[21] K. W. Kang, S. J. Lee, and S. G. Kim, "Molecular mechanism of Nrf2 activation by oxidative stress," Antioxidants and Redox Signaling, vol. 7, no. 11-12, pp. 1664-1673, 2005.

[22] A. Pagano and C. Barazzone-Argiroffo, "Alveolar cell death in hyperoxia-induced lung injury," Annals of the New York Academy of Sciences, vol. 1010, pp. 405-416, 2003.

[23] L. L. Mantell, S. Horowitz, J. M. Davis, and J. A. Kazzaz, "Hyperoxia-induced cell death in the lung-the correlation of apoptosis, necrosis, and inflammation," Annals of the New York Academy of Sciences, vol. 887, pp. 171-180, 1999.

[24] J. D. Crapo, "Morphologic changes in pulmonary oxygen toxicity," Annual Review of Physiology, vol. 48, pp. 721-731, 1986.

[25] J. D. Crapo, B. E. Barry, L. Y. Chang, and R. R. Mercer, "Alterations in lung structure caused by inhalation of oxidants," Journal of Toxicology and Environmental Health, vol. 13, no. 2-3, pp. 301-321, 1984.

[26] J. D. Crapo and D. F. Tierney, "Superoxide dismutase and pulmonary oxygen toxicity," American Journal of Physiology, vol. 226, no. 6, pp. 1401-1407, 1974.

[27] S. M. Mensack and R. Murtaugh, "Oxygen toxicity," Compendium on Continuing Education for the Practicing Veterinarian, vol. 21, no. 4, pp. 341-351, 1999.

[28] J. Romashko III, S. Horowitz, W. R. Franek et al., "MAPK pathways mediate hyperoxia-induced oncotic cell death in lung epithelial cells," Free Radical Biology and Medicine, vol. 35, no. 8, pp. 978-993, 2003.

[29] S. Kannan, H. Pang, D. C. Foster, Z. Rao, and M. Wu, "Human 8-oxoguanine DNA glycosylase increases resistance to hyperoxic cytotoxicity in lung epithelial cells and involvement with altered MAPK activity," Cell Death and Differentiation, vol. 13, no. 2, pp. 311-323, 2006.

[30] L. F. Li, S. K. Liao, Y. S. Ko, C. H. Lee, and D. A. Quinn, "Hyperoxia increases ventilator-induced lung injury via mitogenactivated protein kinases: a prospective, controlled animal experiment," Critical Care, vol. 11, no. 1, Article ID R25, 2007.

[31] S. Papaiahgari, S. R. Kleeberger, H. Y. Cho, D. V. Kalvakolanu, and S. P. Reddy, "NADPH oxidase and ERK signaling regulates hyperoxia-induced Nrf2-ARE transcriptional response in pulmonary epithelial cells," Journal of Biological Chemistry, vol. 279, no. 40, pp. 42302-42312, 2004.

[32] S. T. Qureshi, X. Zhang, E. Aberg et al., "Inducible activation of TLR4 confers resistance to hyperoxia-induced pulmonary apoptosis," Journal of Immunology, vol. 176, no. 8, pp. 49504958, 2006.

[33] L. L. Mantell and P. J. Lee, "Signal transduction pathways in hyperoxia-induced lung cell death," Molecular Genetics and Metabolism, vol. 71, no. 1-2, pp. 359-370, 2000.

[34] T. E. Zaher, E. J. Miller, D. M. Morrow, M. Javdan, and L. L. Mantell, "Hyperoxia-induced signal transduction pathways in pulmonary epithelial cells," Free Radical Biology and Medicine, vol. 42, no. 7, pp. 897-908, 2007.

[35] A. B. Waxman and N. Kolliputi, "IL-6 protects against hyperoxia-induced mitochondrial damage via BCL-2 induced
BAK interactions with mitofusions," American Journal of Respiratory Cell and Molecular Biology, vol. 41, no. 4, pp. 385-396, 2009.

[36] D. Barlos, E. A. Deitch, A. C. Watkins et al., "Traumahemorrhagic shock-induced pulmonary epithelial and endothelial cell injury utilizes different programmed cell death signaling pathways," American Journal of Physiology, vol. 296, no. 3, pp. L404-L417, 2009.

[37] G. R. Budinger and J. I. Sznajder, "To live or die: a critical decision for the lung," Journal of Clinical Investigation, vol. 115, no. 4, pp. 828-830, 2005.

[38] A. C. Kulkarni, P. Kuppusamy, and N. Parinandi, "Oxygen, the lead actor in the pathophysiologic drama: enactment of the trinity of normoxia, hypoxia, and hyperoxia in disease and therapy," Antioxidants and Redox Signaling, vol. 9, no. 10, pp. 1717-1730, 2007.

[39] L. Min and X. Jian-xing, "Detoxifying function of cytochrome c against oxygen toxicity," Mitochondrion, vol. 7, no. 1-2, pp. 13-16, 2007.

[40] M. Czarna and W. Jarmuszkiewicz, "Role of mitochondria in reactive oxygen species generation and removal; relevance to signaling and programmed cell death," Postepy Biochemii, vol. 52, no. 2, pp. 145-156, 2006.

[41] P. Jezek and L. Hlavata, "Mitochondria in homeostasis of reactive oxygen species in cell, tissues, and organism," International Journal of Biochemistry and Cell Biology, vol. 37, no. 12, pp. 2478-2503, 2005.

[42] M. Valko, D. Leibfritz, J. Moncol, M. T. Cronin, M. Mazur, and J. Telser, "Free radicals and antioxidants in normal physiological functions and human disease," International Journal of Biochemistry and Cell Biology, vol. 39, no. 1, pp. 44-84, 2007.

[43] V. Tandon, B. M. Gupta, and R. Tandon, "Free radicals/reactive oxygen species," JK Practitioner, vol. 12, no. 3, pp. 143-148, 2005.

[44] K. Apel and H. Hirt, "Reactive oxygen species: metabolism, oxidative stress, and signal transduction," Annual Review of Plant Biology, vol. 55, pp. 373-399, 2004.

[45] V. Sakac and M. Sakac, "Free oxygen radiacals and kidney diseases-part I," Medicinski Pregled, vol. 53, no. 9-10, pp. 463-474, 2000.

[46] E. Cadenas, "Biochemistry of oxygen toxicity," Annual Review of Biochemistry, vol. 58, pp. 79-110, 1989.

[47] E. Cadenas and K. J. Davies, "Mitochondrial free radical generation, oxidative stress, and aging," Free Radical Biology and Medicine, vol. 29, no. 3-4, pp. 222-230, 2000.

[48] S. A. Comhair, P. R. Bhathena, C. Farver, F. B. Thunnissen, and S. C. Erzurum, "Extracellular glutathione peroxidase induction in asthmatic lungs: evidence for redox regulation of expression in human airway epithelial cells," FASEB Journal, vol. 15, no. 1, pp. 70-78, 2001.

[49] K. J. Davies, "Oxidative stress: the paradox of aerobic life," Biochemical Society Symposium, vol. 61, pp. 1-31, 1995.

[50] R. Kohen and A. Nyska, "Oxidation of biological systems: oxidative stress phenomena, antioxidants, redox reactions, and methods for their quantification," Toxicologic Pathology, vol. 30, no. 6, pp. 620-650, 2002.

[51] L. A. Pham-Huy, H. He, and C. Pham-Huy, "Free radicals, antioxidants in disease and health," International Journal of Biomedical Science, vol. 4, no. 2, pp. 89-96, 2008.

[52] M. Nishikawa and M. Inoue, "Oxidative stress and tissue injury," Japanese Journal of Anesthesiology, vol. 57, no. 3, pp. 321-326, 2008.

[53] R. Chang, Chemistry, McGraw Hill, Boston, Mass, USA, 9th edition, 2007. 
[54] W. Droge, "Free radicals in the physiological control of cell function," Physiological Reviews, vol. 82, no. 1, pp. 47-95, 2002.

[55] D. Hernandez-Saavedra and J. M. McCord, "Evolution and free radicals. Importance of oxidative stress in human pathology," Revista Medica del Instituto Mexicano del Seguro Social, vol. 45, no. 5, pp. 477-484, 2007.

[56] B. Halliwell, R. Aeschbach, J. Loliger, and O. I. Aruoma, "The characterization of antioxidants," Food and Chemical Toxicology, vol. 33, no. 7, pp. 601-617, 1995.

[57] B. Halliwell, "How to characterize a biological antioxidant," Free Radical Research Communications, vol. 9, no. 1, pp. 1-32, 1990.

[58] L. J. Buccellato, M. Tso, O. I. Akinci, N. S. Chandel, and G. R. Budinger, "Reactive oxygen species are required for hyperoxiainduced Bax activation and cell death in alveolar epithelial cells," Journal of Biological Chemistry, vol. 279, no. 8, pp. 6753 6760, 2004.

[59] E. M. Bulger and R. V. Maier, "Antioxidants in critical illness," Archives of Surgery, vol. 136, no. 10, pp. 1201-1207, 2001.

[60] S. Yamaoka, H. S. Kim, T. Ogihara et al., "Severe vitamin E deficiency exacerbates acute hyperoxic lung injury associated with increased oxidative stress and inflammation," Free Radical Research, vol. 42, no. 6, pp. 602-612, 2008.

[61] N. Noguchi, A. Watanabe, and H. Shi, "Diverse functions of antioxidants," Free Radical Research, vol. 33, no. 6, pp. 809 817,2000

[62] M. F. Tsan, "Superoxide dismutase and pulmonary oxygen toxicity: lessons from transgenic and knockout mice (Review)," International Journal of Molecular Medicine, vol. 7, no. 1, pp. 13-19, 2001.

[63] J. M. van Raamsdonk and S. Hekimi, "Deletion of the mitochondrial superoxide dismutase sod-2 extends lifespan in caenorhabditis elegans," PLoS Genetics, vol. 5, no. 2, Article ID e1000361, 2009.

[64] R. L. Auten, M. A. O’Reilly, T. D. Oury, E. Nozik-Grayck, and M. H. Whorton, "Transgenic extracellular superoxide dismutase protects postnatal alveolar epithelial proliferation and development during hyperoxia," American Journal of Physiology, vol. 290, no. 1, pp. L32-L40, 2006.

[65] R. P. Bowler, J. Arcaroli, J. D. Crapo, A. Ross, J. W. Slot, and E. Abraham, "Extracellular superoxide dismutase attenuates lung injury after hemorrhage," American Journal of Respiratory and Critical Care Medicine, vol. 164, no. 2, pp. 290-294, 2001.

[66] F. Gao, V. L. Kinnula, M. Myllarniemi, and T. D. Oury, "Extracellular superoxide dismutase in pulmonary fibrosis," Antioxidants and Redox Signaling, vol. 10, no. 2, pp. 343-354, 2008.

[67] E. Nozik-Grayck, H. B. Suliman, and C. A. Piantadosi, "Extracellular superoxide dismutase," International Journal of Biochemistry and Cell Biology, vol. 37, no. 12, pp. 2466-2471, 2005.

[68] R. J. Folz, A. M. Abushamaa, and H. B. Suliman, "Extracellular superoxide dismutase in the airways of transgenic mice reduces inflammation and attenuates lung toxicity following hyperoxia," Journal of Clinical Investigation, vol. 103, no. 7, pp. 1055-1066, 1999.

[69] D. J. O’Donovan and C. J. Fernandes, "Mitochondrial glutathione and oxidative stress: implications for pulmonary oxygen toxicity in premature infants," Molecular Genetics and Metabolism, vol. 71, no. 1-2, pp. 352-358, 2000.

[70] A. R. Smith, F. Visioli, and T. M. Hagen, "Vitamin C matters: increased oxidative stress in cultured human aortic endothelial cells without supplemental ascorbic acid," FASEB Journal, vol. 16, no. 9, pp. 1102-1104, 2002.

[71] H. Shi and K. J. Liu, "Effects of glucose concentration on redox status in rat primary cortical neurons under hypoxia," Neuroscience Letters, vol. 410, no. 1, pp. 57-61, 2006.

[72] M. K. Misra, M. Sarwat, P. Bhakuni, R. Tuteja, and N. Tuteja, "Oxidative stress and ischemic myocardial syndromes," Medical Science Monitor, vol. 15, no. 10, pp. RA209-RA219, 2009.

[73] J. Tkaczyk and M. VIzek, "Oxidative stress in the lung tissuesources of reactive oxygen species and antioxidant defence," Prague Medical Report, vol. 108, no. 2, pp. 105-114, 2007.

[74] L. B. Ware, "Pathophysiology of acute lung injury and the acute respiratory distress syndrome," Seminars in Respiratory and Critical Care Medicine, vol. 27, no. 4, pp. 337-349, 2006.

[75] F. Frutos-Vivar, N. D. Ferguson, and A. Esteban, "Epidemiology of acute lung injury and acute respiratory distress syndrome," Seminars in Respiratory and Critical Care Medicine, vol. 27, no. 4, pp. 327-336, 2006.

[76] K. Nagata, Y. Iwasaki, T. Yamada et al., "Overexpression of manganese superoxide dismutase by $\mathrm{N}$-acetylcysteine in hyperoxic lung injury," Respiratory Medicine, vol. 101, no. 4, pp. 800-807, 2007.

[77] E. Manteiga Riestra, O. Martinez Gonzalez, and F. Frutos Vivar, "Epidemiology of acute pulmonary injury and acute respiratory distress syndrome," Medicina Intensiva, vol. 30, no. 4, pp. 151-161, 2006.

[78] T. G. Brock and C. Di Giulio, "Prolonged exposure to hyperoxia increases perivascular mast cells in rat lungs," Journal of Histochemistry and Cytochemistry, vol. 54, no. 11, pp. 12391246, 2006.

[79] L. Wang, J. A. Bastarache, N. Wickersham, X. Fang, M. A. Matthay, and L. B. Ware, "Novel role of the human alveolar epithelium in regulating intra-alveolar coagulation," American Journal of Respiratory Cell and Molecular Biology, vol. 36, no. 4, pp. 497-503, 2007.

[80] G. D. Leikauf, S. A. McDowell, C. J. Bachurski et al., "Functional genomics of oxidant-induced lung injury," Advances in Experimental Medicine and Biology, vol. 500, pp. 479-487, 2001.

[81] G. Matute-Bello, C. W. Frevert, and T. R. Martin, "Animal models of acute lung injury," American Journal of Physiology, vol. 295, no. 3, pp. L379-L399, 2008.

[82] M. A. Matthay, G. A. Zimmerman, C. Esmon et al., "Future research directions in acute lung injury: summary of a national heart, lung, and blood institute working group," American Journal of Respiratory and Critical Care Medicine, vol. 167, no. 7, pp. 1027-1035, 2003.

[83] C. Flores, S. F. Ma, K. Maresso, O. Ahmed, and J. G. N. Garcia, "Genomics of acute lung injury," Seminars in Respiratory and Critical Care Medicine, vol. 27, no. 4, pp. 389-395, 2006.

[84] G. D. Rubenfeld, E. Caldwell, E. Peabody et al., "Incidence and outcomes of acute lung injury," New England Journal of Medicine, vol. 353, no. 16, pp. 1685-1693, 2005. 


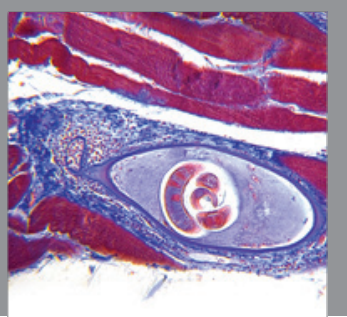

Gastroenterology

Research and Practice
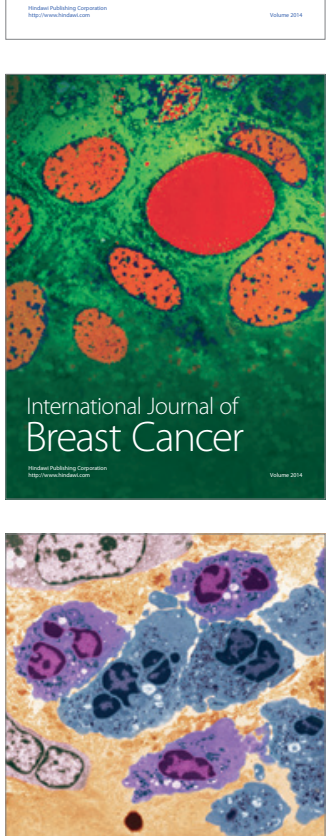

International Journal of Inflammation
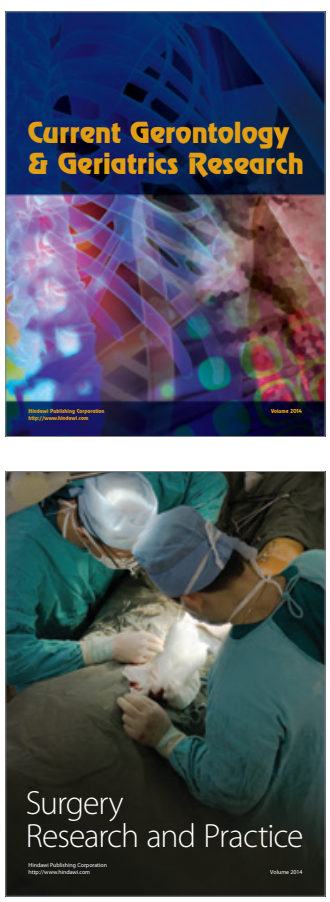
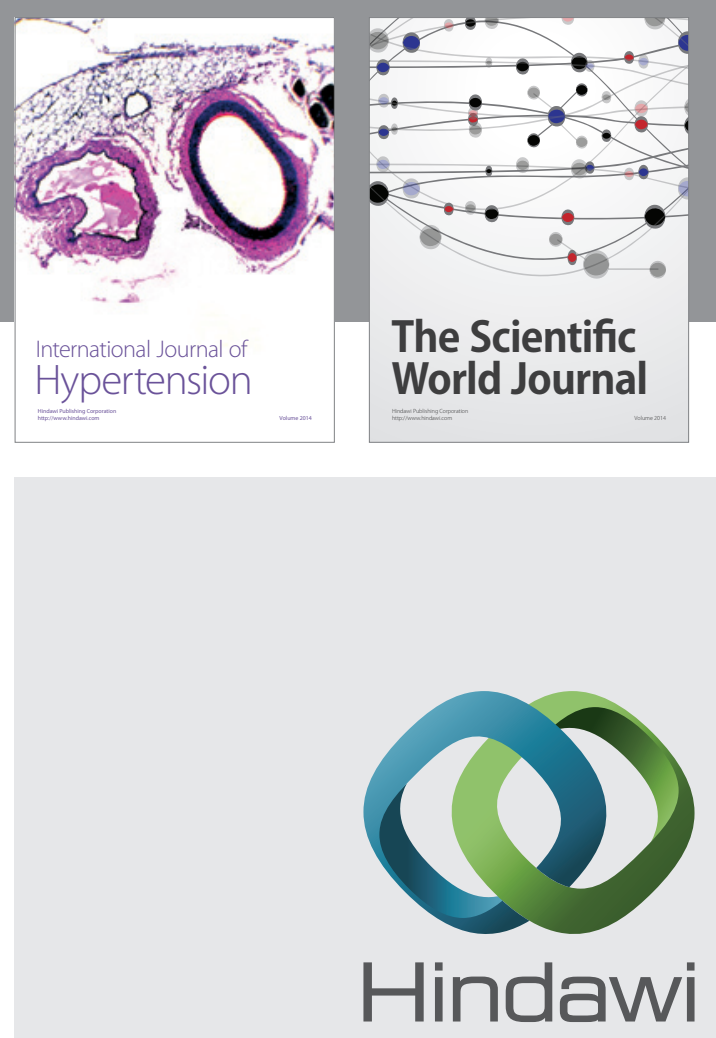

Submit your manuscripts at

http://www.hindawi.com
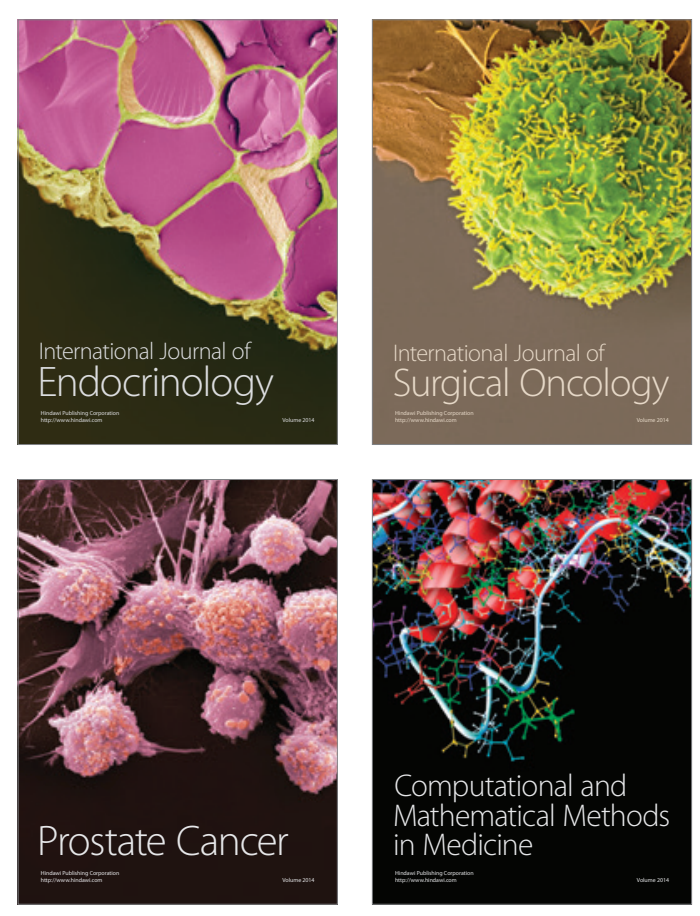
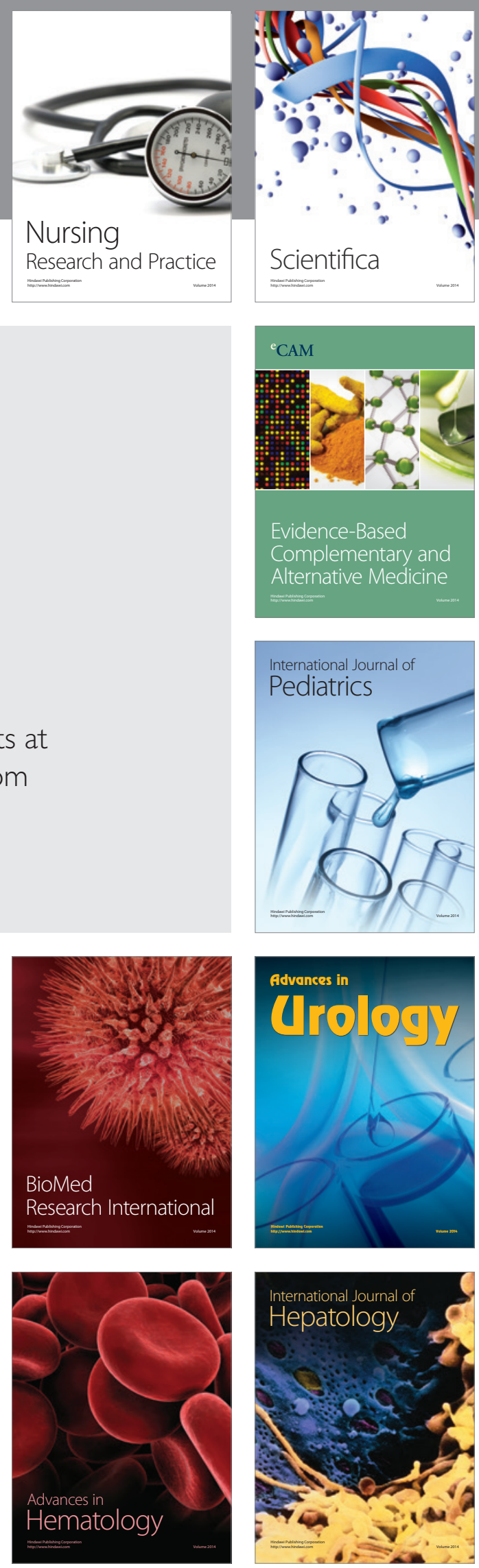